\title{
PERANAN ARAH KIBLAT TERHADAP IBADAH SHALAT
}

\author{
Bustanul Iman RN \\ Sekolah Tinggi Agama Islam (STAI) DDI AD Mangkoso \\ Email; bustanulimanrn@gmail.com
}

\begin{abstract}
The scholars of jurisprudence differed in addressing the problems facing the Qibla/ Kaaba. Imam Shafi'i and most of his followers require the Muslims to go to 'ain al-Ka'bah. Medium Jumhur Ulama other than Shafi'iyah for Muslims whose region is far from the Ka'bah is quite facing to jihat al-Ka'bah. While Indonesian Muslims are required to face 'ain al-Ka'bah in performing worship prayer ie to the northwest according to the position of each place, although facing to the West exactly the shalat is still valid. However, if facing to 'ain al-Ka'bah its validity will be more perfect. For that reason for the area of Indonesia mosque kiblatnya less accurate directions to be rearranged shafnya and not have to dismantle the building.
\end{abstract}

Abstrak: Para Ulama berbeda pendapat dalam menyikapi masalah menghadap ke kiblat/Ka'bah. Imam Syafi'i dan sebagian besar pengikutnya mengharuskan kepada umat Islam untuk menghadap ke 'ain al-Ka'bah. Sedang Jumhur Ulama selain Syafi'iyah bagi umat Islam yang kawasannya jauh dari Ka'bah cukup menghadap ke jihat al-Ka'bah. Sedangkan umat Islam Indonesia diharuskan untuk menghadap ke 'ain al-Ka'bah dalam melakukan ibadah shalat yaitu ke barat laut sesuai posisi tempat masing-masing, walaupun menghadap ke arah Barat persis shalatnya tetap sah. Akan tetapi apabila menghadap ke 'ain al-Ka'bah keabsahannya akan lebih sempurna. Untuk itu bagi kawasan Indonesia yang masjid arah kiblatnya kurang akurat supaya ditata ulang shafnya dan tidak harus membongkar bangunannya.

Kata Kunci: Arah Kiblat, Ibadah Shalat,Ka’bah

\section{PENDAHULUAN}

Menghadap kiblat merupakan salah satu syarat sahnya shalat ${ }^{1}$. Apabila tidak mengadap kiblat maka shalatnya tidak sah. Beberapa waktu yang lalu umat Islam Indonesia digemparkan isu bergesernya arah kiblat masjid-masjid di Indonesia, bahkan dengan temuan hasil penelitian/pengukuran dengan metode ukur satelit lewat Global Positioning

System (GPS) berkat jasa Google Earth sekitar $70 \%$ masjid di seluruh Indonesia arah kiblatnya tidak akurat lagi, karena seringnya terjadi gempa bumi yang mengakibatkan lempenglempeng bumi itu bergeser. Akibatnya umat Islam Indonesia menjadi resah karena khawatir shalatnya tidah sah karena arah kiblatnya bergeser, ta'mir masjid/mushalla seakan-akan tergugat 
perihal keabsahan shalat warga jama'ahnya.

Diberitakan pergeseran itu mencapai $35 \mathrm{~cm}$ dari posisi semula, bahkan menurut ahli Peneliti Matahari dan Astronomi; Prof. Dr. H. Thomas Djamaluddin, M.Sc. dari LAPAN (Lembaga Antariksa dan Penerbangan Nasional) Bandung, mengatakan bahwa bumi memang bergeser dan setiap tahun pergeseran itu mencapai sekitar $7 \mathrm{~cm}^{2}$ Dengan pergeseran yang relatif kecil, tidak akan merubah posisi dan arah kiblat masjid.

Kemudian umat bertanya kepada Majlis Ulama Indonesia (MUI) pusat untuk menjawab pertanyaanpertanyaan tersebut. Ia tidak boleh membiarkan umat dalam keadaan tidak tahu terus menerus atau dalam kebingungan karena hal itu akan membahayakan umat sebagai fihak mustafti baik secara i'tiqadi maupun syar' $i{ }^{3}$ Meskipun demikian, mufti harus berhati-hati dan bijak dalam memberikan jawabannya. Ia tidak boleh tergesa-gesa memberikan jawaban sebelum mengetahui hakekat persoalan yang ditanyakan umat.

Disamping itu ia juga harus melakukan kajian yang mendalam menggunakan dalil-dalil syara', mencurahkan segenap kemampuan intelektualnya dalam menjawab pertanyaan-pertanyaan tersebut. Guna menjawab pertanyaan masyarakat hukum arah kiblat, Majlis Ulama Indonesia (MUI) pusat menyelenggarakan rapat komisi Fatwa pada tanggal 1 Pebruari 2010 membahas makalah Prof. Dr. KH. Ali Musthafa Ya'kub, MA. Dan dikeluarkan fatwa MUI Nomor 03 tahun 2010 tentang kiblat. Butir 3 penetapan fatwa menyatakan bahwa "Letak Geografis Indonesia yang berada di bagian timur Ka'bah/Makkah, maka arah kiblat umat Islam di Indonesia adalah menghadap ke arah barat".

Rekomendasi yang disertakan mengharap agar bangunan masjid/mushalla di Indonesia sepanjang kiblatnya ke arah barat, tidak perlu diubah, dibongkar dan sebagainya. Penetapan butir ke 3 fatwa tersebut mengundang kesimpangsiuran penafsiran mengenai hukum keabsahan shalat yang kiblatnya ke barat laut.

Arah barat laut sebagai kiblat untuk kawasan pulau Sulawesi (LS) mengacu pada pedoman 'ain al$K a$ 'bah (bangunan fisik ka'bah) yang merupakan pandangan mayoritas ulama Syafi'iyah. Tanpa mengubah sama sekali dasar hukum yang mendasari fatwa MUI No. 03/2010 yang terdiri dari 5 (lima) ayat alQur'an, 6 (enam) hadis dan 4 (empat) doktrin Fuqaha dari keempat madzhab sunni, diterbitkan setara revisi berupa fatwa MUI No.05 th. 2010 tertanggal 1 Juli 2010. Rapat Komisi Fatwa MUI (Pusat) setelah membahas makalah Drs. KH. Ghozali Masruri yang berjudul Arah Kiblat di Indonesia Revisi dilokalisir pada butir ke 3 penetapan menjadi berbunyi Kiblat umat Islam Indonesia adalah 
menghadap ke barat laut dengan posisi bervariasi sesuai dengan letak kawasan masing-masing. Rekomendasi fatwa berharap agar bangunan masjid/mushalla yang tidak tepat arah kiblatnya perlu ditata ulang shafnya tanpa membongkar bangunannya. Diktum penetapan fatwa butir ke 3 sama-sama menyarankan agar bangunan masjid/mushalla yang ada tidak perlu diubah atau dibongkar. Hanya kalau dipandang perlu melakukan penataan ulang shafnya. Perbedaan yang kontroversial terletak pada kata arah barat (fatwa MUI No. 03 th. 2010) dan barat laut lengkap kalimat rangkaiannya pada fatwa MUI No. 05 th. 2010.

Tulisan ini akan mengkaji lebih jauh tentang pergeseran lempenglempeng bumi yang menyebabkan bergesernya arah kiblat masjid.

\section{PEMBAHASAN}

\section{A. Dalil Tentang Arah Kiblat}

Menghadap kiblat itu berkaitan dengan ritual ibadah yakni shalat, maka ia baru boleh dilakukan setelah adanya dalil yang menunjukkan bahwa menghadap kiblat itu wajib. Hal ini sesuai dengan kaidah fiqhiyah "al-ashl fi al ibadah al-buthlan hatta yaquma al-dalil 'ala al-amr'. "hukum pokok dal;am lapangan ibadah itu adalah bathal sampai ada dalil yang memerintahkannya". Ini berarti bahwa dalam lapangan ibadah, pada hakekatnya segala perbuatan harus adanya perintah yang datangnya dari
Allah dan Rasul-Nya baik melalui alQur'an maupun as-Sunnah. Ada beberapa nash yang memerintahkan kita untuk menghadap kiblat dalam shalat baik melalui nash al-Qur'an ataupun as-Sunnah. Adapun nash-nash al-Qur'an adalah sebagai berikut.

1. Q.S. Al-Baqarah /2: 144.

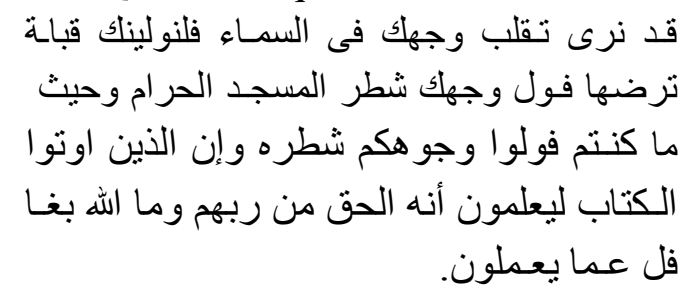

Terjemahnya:

"Sungguh kami (sering) melihat wajahmu menengadah ke langit, maka sungguh Kami akan memalingkan kamu ke kiblat yang kamu sukai. Palingkanlah wajahmu ke arah Masjid al-Haram. Dan dimana saja kamu berada, palingkanlah wajahmu ke arahnya. Dan sesungguhnya orang-orang (Yahudi dan Nasrani) yang diberi kitab (Taurat dan Injil) memang mengetahui, bahwa berpaling ke Masjid al-Haram itu adalah benar dari Tuhannya; dan Allhah sekalikali tidak lengah dari apa yang mereka kerjakan". 5

2. Q.S. Al-Baqarah /2 : 149 dan 150.

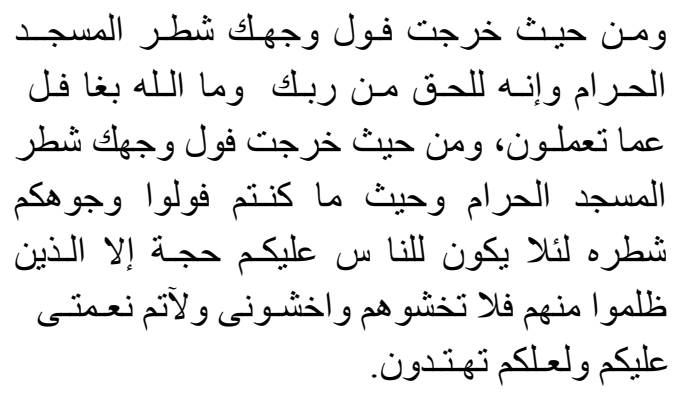

Terjemahnya: 
"Dan dari mana saja kamu ke luar (datang), maka palingkanlah wajahmu ke arah Masjid alHaram; sesungguhnya ketentuan itu benar-benar sesuatu yang hak dari Tuhanmu. Dan Allah sekalikali tidak lengah dari apa yang telah kamu kerjakan. Dan dari mana saja kamu keluar, maka palingkanlah wajahmu ke arah Masjid al-Haram. Dan di mana saja kamu (sekalian) berada, maka palingkanlah wajahmu ke arahnya, agar tidak ada hujjah bagi manusia atas kamu, kecuali orang-orang yang dzalim di antara mereka. Maka janganlah kamu takut kepada mereka dan takutlah kepada-Ku. Dan agar Kusempurnakan ni'matKu atasmu, dan supaya kamu mendapat petunjuk", 6

Dalam ayat-ayat tersebut Allah فول وجهك شطر المسـد الحرام mengulang dalam firman-Nya sampai tiga kali. Menurut Ibn Abbas, pengulangan tersebut berfungsi sebagai penegasan pentingnya menghadap kiblat ( $t a{ }^{\prime} k i d$ ). Sementara itu menurut Fahruddin ar Razi, pengulangan tersebut menunjukkan fungsi yang berbedabeda. Pada ayat yang pertama (alBaqarah :144 ) ungkapan tersebut dutujukan kepada orang-orang yang dapat melihat Ka'bah, sedangkan pada ayat yang kedua (al-Baqarah : 149) ungkapan tersebut ditujukan kepada orang-orang yang berada di luar Masjid al-Haram. Sementara pada ayat yang ketiga (al-Baqarah : 150) ungkapan tersebut ditujukan kepada orang-orang yang berada di negerinegeri yang jauh. ${ }^{7}$ Berdasarkan kedua pendapat tersebut jelaslah bahwa perintah menghadap Kiblat itu tidak hanya ditujukan kepada mereka yang berada di Makkah dan sekitarnya saja, tetapi juga bagi semua umat Islam di manapun mereka berada.

Adapun hadis-hadis Nabi saw. yang secara tegas menyebutkan kewajiban menghadap kiblat dalam shalat adalah :

1. Hadis yang diriwayatkan oleh Imam Bukhari dan Muslim.

$$
\begin{aligned}
& \text { عن ابى هريرة ر.ع. قال : قال النبى ص.م.: }
\end{aligned}
$$

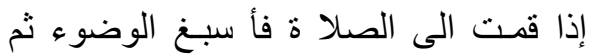

$$
\begin{aligned}
& \text { استقبـل القبلة وكبر. }
\end{aligned}
$$

Artinya:

"Dari Abu Hurairah r.a. Nabi saw. bersabda: bila hendak shalat maka sempurnakanlah berwudlu, lalu menghadap kiblat kemudian takbir (shalat). ${ }^{8}$

2. Hadis yang diriwayatkan oleh Imam Muslim.

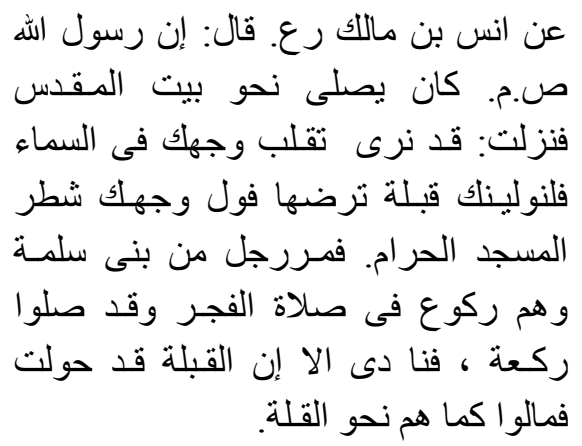

Artinya:

"Dari Anas bin Malik ra. bahwa Rasulullah saw. (pada suatu hari) sedang shalat menghadap ke Bait al-Maqdis, kemudian turunlah ayat "Sungguh kami melihat wajahmu 
menengadah ke langit (sering melihat ke langit berdo'a agar turun wahyu yang memerintahkan berpaling ke Baitullah). Sungguh kami palingkan wajahmu ke kiblat yang kamu sukai. Palingkanlah wajahmu ke arah Masjid alHaram". Kemudian ada orang dari Bani Salamah sedang melakukan ruku' pada shalat fajar pada raka'at kedua. Lalu Nabi menyeru "Ingatlah bahwa kiblat telah diubah”. Lalu, mereka berpaling ke arah kiblat (Baitullah). ${ }^{9}$

3. Hadis yang diriwayatkan oleh Imam Baihaqi.

البيت قبلة لآهل المسـجد والمسبد قبـلة

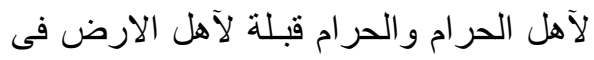
مشار قهـا ومغا ربها من أمتى (رواه (البيهقى). منيار).

Artinya:

"Baitullah (Ka'bah) adalah kiblat bag orang-orang yang dalam masjid (Masjid al-Haram), dan masjid (Masjid al-Haram) adalah kiblat bagi orang-orang yang tinggal di Tanah Haram (Makkah), dan Tanah Haram (Makkah) adalah kiblat bagi seluruh penduduk bumi, timur dan barat dari umatku. (Hadis riwayat Imam Baihaqi). ${ }^{10}$

Hadis yang pertama memperkuat perintah menghadap kiblat yang terdapat dalam al-Qur'an sehingga hadis tersebut dan hadis-hadis yang lainnya semakna berfungsi sebagai bayan ta'kid. Lebih dari itu, hadis yang kedua lebih mengokohkan fungsinya sebagai bayan ta'kid karena adanya perintah Nabi saw. untuk membetulkan arah kiblat yang keliru. ${ }^{11}$ Dan hadis yang ketiga memperbolehkan bagi orang yang jauh untuk menghadap ke arah Tanah Haram tidak harus ke Ka'bah. Menurut Hasjim Abbas. ${ }^{12}$ Teks hadis tersebut termuat dalam Tafsir al-Jami 'li ahkami al-Quir'an karya Imam Qurthubi pada jilid I hal. 562 dan dalam Tafsir Ibnu Katsir jilid I hal. 240. Kehujjahan hadis tersebut menurut evaluasi Imam Baihaqie dinyatakan berstatus dha'if, karena pada sanad hadis terdata "tafarrud" yang dilakukan oleh Umar bin Hafash al-Makki. Periwayat tersebut tergolong dha'if.

\section{B. Arah Kiblat dan Ibadah Shalat}

Sebelum penulis membahas lebih lanjut, terlebih dahulu penulis paparkan tentang fenomena alam yaitu terjadinya gempa bumi yang mengakibatkan lempeng-lempeng bumi bergeser, akhirnya timbul kesan dengan adanya pergeseran lempenglempeng bumi, maka sekitar $70 \%$ masjid-masjid di Indonesia arah kiblatnya berubah dari posisi semula sehingga tidak akurat lagi. Bahkan menurut informasi yang telah disampaikan oleh ketua MUI pusat, Drs. KH. Amidhan di media elektronic beliau mengatakan bahwa masjidmasjid di Indonesia bergeser sekitar 35 centi meter dari posisi semula. Padahal menurut ahli peneliti matahari dan astronomi dari LAPAN Bandung, Prof. Dr. H. Tomas Djamaluddin, 
M.Sc. bumi setiap tahun bergeser sekitar 7 centi meter.

Perubahan yang relatif sangat kecil itu menurut penulis sangat tidak berpengaruh pada masjid dari posisi arah kiblat semula (kalau pada waktu membangun ukurannya sudah pas). Sebab kalau dihitung bahwa $1^{0}$ Lintang paralel jaraknya adalah 111 kilo meter (11.100.000 centi meter). Apabila bumi bergeser $7 \mathrm{~cm}$, maka pengaruh busur derajat adalah $7 / 11.100 .000 \mathrm{~cm} \mathrm{x} 1^{0}=00^{0} 00^{\prime} 00.00^{\prime \prime}$ busur. Kalau masjid bergeser $35 \mathrm{~cm}$, berarti perubahan busur derajat adalah $35 / 11.100 .000 \mathrm{~cm} \mathrm{x} 1^{0}=00^{0} 00^{\prime} 0.01$ " busur. Jika bumi bergeser sampai sejauh $1 \mathrm{~km}$ baru akan berpengaruh kepada busur derajat hanya 0000'32.43" itupun membutuhkan waktu yang lama yaitu $100.000 / 7 \mathrm{~cm}$ $\mathrm{x} 1$ tahun $=14.285,71429$ tahun (14.286 th).

Umpama bumi bergeser $2 \mathrm{~km}$ atau 0001'4.86" membutuhkan waktu kurang lebih 28.572 tahun. Pergeseran bumi yang menyebabkan pergeseran arah kiblat masjid sehingga tidak akurat lagi apabila pergeseran itu mencapai $1^{0}$ busur jauhnya. Umpama pengukuran semula suatu masjid kiblatnya $24^{0} 13$ ' kemudian setelah diukur ulang hanya $23^{0} 13^{\prime}$, berarti masjid tersebut bergeser $1^{0}$. Perubahan $1^{0}$ menyebabkan posisi masjid itu tidak lagi lurus dengan Kiblat (Ka'bah), dan itu membutuhkan waktu yang sangat lama sekali yaitu sekitar 1.714.320 tahun.

Sedangkan beberapa masjid yang arah kiblatnya sudah tidak akurat lagi itu bukan akibat dari sering terjadinya gempa bumi dan pergeseran lempenglempeng bumi, melainkan karena waktu membangun yang masih kurang benar (pas) karena biasanya pengukuran diserahkan kepada tukang batu atau yang bukan ahlinya yang penting menghadap ke barat atau dengan pertimbangan indahnya bangunan, seperti beberapa masjid di Kota Parepare yaitu menghadap persis ke arah Barat sehingga arah kiblatnya tidak tepat kurang dari ukuran yang seharusnya yakni $22^{0} 17^{\prime} 49.55^{\prime},{ }^{\prime 3}$ berarti kiblatnya mengarah ke selatan antara Sudan dan Yaman.

Namun ada juga beberapa masjid yang sudah benar, karena pada saat membangun ukuran arah kiblatnya sudah benar walaupun sudah sekian lama berdiri sampai sekarang arah kiblatnya masih akurat.

\section{Kedudukan Kiblat Terkait}

Aqidah.

Menghadap kiblat bagi agama samawi merupakan syiar agama utama karena sangat erat sekali hubungannya dengan kegiatan ritual ibadah, bahkan dalam Islam menghadap kiblat merupakan keharusan yang tidak boleh ditawar lagi termasuk membaringkan janazah di liang lahat, menyembelih binatang dan juga dianjurkan bagi orang yang sedang buang hajat (buang air besar/kecil) supaya menghindar dari kiblat. Agama Hanif Ibrahim dan Isma'il menempatkan Ka'bah yang berada di tengah Masjid al-Haram sebagai 
kiblat. Adapun agama Yahudi yang dianut Bani Israil telah menempatkan Bait al-Maqdis sebagai kiblat. ${ }^{14}$

Pemindahan kiblat dari Bait alMaqdis ke Masjid al-Haram mengakibatkan keributan dan menimbulkan berbagai macam komentar, baik dari orang Islam yang lemah imannya maupun dari orang di luar Islam. ${ }^{15}$ Mereka mengatakan bahwa Muhammad berfikir kurang matang, sebentar menghadap ke sana sebentar menghadap kemari. Ada pula yang mengatakan bahwa Muhammad kembali ke ajaran nenek moyangnya sebab di sekitar Baitullah pada saat itu masih banyak terdapat berhala. Bahkan ada orang yang baru masuk Islam dan belum kuat imannya kembali menjadi kafir. Atas pemindahan kiblat tersebut, orang Yahudi dan orang munafik sangat tidak senang sebab menurut mereka Bait al-Maqdis yang didirikan oleh nabi Sulaiman adalah tempat suci sumber agama yang dibawa oleh nabi keturunan Israil. Maka dengan berkiblatnya Muhammad ke Bait alMaqdis berarti ajaran Muhammad hanyalah plagiat dari ajaran mereka. Sekarang Muhammad berpindah kiblat ke Baitullah, maka sangat kecewalah mereka. Protes terkait aqidah dipelopori sufaha etnis Yahudi ketika Rasulullah Muhammad saw. hingga 16-17 bulan pasca hijrah ke Madinah menjadikan Bait al-Maqdis sebagai kiblat dalam shalat.

Hujatan mereka antara lain Islam tampil dengan corak keagamaan berbeda dengan kita (agama Yahudi), tapi mereka (umat Islam) telah menyerobot kiblat Bait al-Maqdis kita. ${ }^{16}$ Seperti tersurat pada sabab nuzul QS. Al-Baqarah : 142 perintah peralihan kiblat dari Bait al-Maqdis ke Ka'bah di Masjid al-Haram setelah lewat pertengahan tahun ke 2 hijriah, tepatnya pada pertengahan bulan Sya'ban ${ }^{17}$ Ketika diajukan pertanyaan apa sebab arah menghadap dalam shalat pada mulanya ke Bait alMaqdis, kemudian berganti ke Ka'bah/Masjid al- Haram ? Syeikh Muhammad Mutawalli al-Sya'rawi berkenan menjawab : karena saat itu Bait al-Maqdis keberadaannya menampung kesucian yang kondusif untuk ibadah keislaman, pada saat yang sama Ka'bah dan areal Masjid al-Haram dipenuhi oleh patung/berhala persemedian orangorang kafir hingga mereka bangga menyebut sebagai bait al-Arab Sekira umat Islam dalam shalat menghadapkan muka ke Ka'bah berarti memadai ritual kekufuran. ${ }^{18}$ Hipothesa tersebut terbukti benar saat kota Makkah jatuh ke tangan orang Islam (fathu Makkah) segera Ka'bah dan areal Masjid al-Haram dikosongkan dari patung/berhala, karena lokasi itu sebagai representasi "Bait Allah".19

2. Antara Bangunan dan Arah Ka'bah.

Bila pada masa Nabi Muhammad saw. kewajiban menghadap kiblat yakni Ka'bah itu tidak banyak menimbulkan masalah karena umat 
Islam masih relatif sedikit dan kebanyakan tinggal di seputar Makkah sehingga mereka bisa melihat wujud Ka'bah. Berbeda halnya dengan keadaan pasca Nabi saw. Saat ini umat Islam sudah banyak jumlahnya dan tinggal tersebar di berbagai belahan dunia yang jauh dari Makkah. Apakah kewajiban menghadap kiblat itu harus pada fisik Ka'bah ('ain al-Ka'bah) atau cukup hanya dengan arahnya saja (jihat al-Ka'bah).

Para Ulama sepakat bahwa menghadap kiblat saat shalat bagi orang -orang yang berada di sekitar Ka'bah atau dapat melihat Ka'bah wajib menghadap lurus ke bangunan fisik Ka'bah ('ain al-Ka'bah) dengan penuh keyakinan. Demikian pula kondisi serupa bagi yang berada di sekitar masjid/mushalla yang pernah dijadikan lokasi permanen atau pernah disinggahi oleh Nabi saw. dan beliau menunaikan shalat di dalamnya, maka bangunan mihrab (tempat imam shalat) berkedudukan menggantikan 'ain al-Ka'bah. ${ }^{20}$ Akurasi posisi mihrab sebagai kiblat terjamin oleh validitas ijtihad Nabi saw.

Imam Syafi'i (w. $204 \quad$ H) menentukan hukum yang sama ('ain $a l-K a$ 'bah) sekalipun bagi orang yang keberadaannya jauh dari Masjid alHaram. Pandangan tersebut termaktub dalam al-Umm. ${ }^{21}$ Rumusan hukum tersebut mewarnai hampir seluruh kitab-kitab Syafi'iyah.

Sementara itu bagi mereka yang tidak dapat melihat Ka'bah, maka para Ulama berbeda pendapat.
Pertama, Ulama Syafi'iyah berpendapat bahwa diwajibkan bagi yang jauh dari Makkah untuk menghadap 'ain al-Ka'bah karena menurut Imam Syafi'i, orang yang mewajibkan menghadap kiblat berarti mewajibkan pula untuk menghadap bangunan ka'bah seperti penduduk Makkah. ${ }^{22}$ Hal ini berdasarkan QS. AlBaqarah : 150. Ayat tersebut mewajibkan kita untuk menghadap ka'bah yang berarti wajib menghadap fisik ka'bah sebagaimana orang yang dapat melihat ka'bah secara langsung. ${ }^{23}$ Disamping itu mereka mendasarkan hadis Ibn Abbas $^{24}$ yang berbunyi :

لمـا دخل النبي صلى الله عليهـ وسلـم البيت دعا

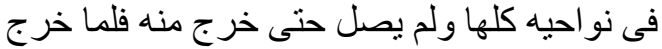
ركع ركعتين فى قبل الكعبة وقال هذه القبلة Artinya:

"Ketika Nabi saw. masuk ke dalam Ka'bah, beliau berdo'a di seluruh sisinya dan tidak melakukan shalat hingga beliau keluar darinya. Beliau kemudian shalat dua rakaat dengan memandang Ka'bah lalu bersabda: "Inilah kiblat".

Kedua, Jumhur Ulama selain Syafi'iyah berpendapat cukup dengan menghadap arah Ka'bah (jihat alKa'bah).

Adapun dalil yang dikemukakan oleh Jumhur ulama adalah sabda Nabi saw. yang diriwayatkan oleh Imam Ibn Majah dan al-Tirmidzi yang berbunyi : عن أبى هـريرة قال : قال رسول الله صلى الله

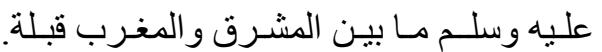
Artinya:

"Dari Abu Hurairah berkata: 
Rasulullah saw. bersabda, Apa yang berada di antara Timur dan Barat adalah Kiblat". ${ }^{25}$

Secara lahiriyah hadis tersebut menunjukkan bahwa semua arah yang berada di antara keduanya yaitu utara dan selatan termasuk kiblat. Sebab, bila diwajibkan menghadap fisik Ka'bah maka tidak sah shalatnya orang-orang yang berada dalam shaff yang panjang yang jauh dari Ka'bah karena tidak bisa memastikan shalatnya menghadap fisik Ka'bah. ${ }^{26}$ Padahal umat Islam sudah sepakat bahwa shalatnya orang-orang tersebut adalah sah karena yang diwajibkan bagi mereka yang tidak dapat melihat Ka'bah adalah menghadap ke arah Ka'bah (jihat al-Ka'bah). ${ }^{27}$

Resiko yang harus dilakukan apabila menghadap 'ain al-Ka'bah (bangunan fisik Ka'bah) merupakan keharusan dan tidak ada jalan untuk bisa mengetahuinya kecuali harus mempelajari petunjuk-petunjuk kiblat, menurut Imam Fahruddin al-Razi adalah kewajiban bagi setiap muslim yang mukallaf untuk mempelajarinya (ومالايتنأدى الواجب الابـه فهو واجب), karena hal tersebut integral dengan kebutuhan memenuhi syarat keabsahan shalat. ${ }^{28}$

3. Mengetahui Arah Kiblat.

Untuk mengetahui arah kiblat yang akurat, ada beberapa cara yang dapat dilakukan antara lain:

a. Dengan perpedoman kepada matahari yaitu pada saat matahari berkulminasi datas Ka'bah. Untuk mengengetahui kapan matahari berkulminasi di atas Ka'bah yang biasa disebut "Rahdu al-Kiblat" adalah apabila Lintang Ka'bah (urdu al-Ka'bah) besarnya sama dengan Deklinasi Matahri (mail al-syams) atau mendekati sama, dan hal ini akan terjadi satu tahun dua kali yaitu setiap tanggal 28 Mei sekitar pukul. 16:18 WIB dan tanggal 16 Juli sekitar pukul. 16:27 WIB. Pada tanggal dan jam tersebut matahari akan berkulminasi di atas Ka'bah sehingga semua benda yang berdiri tegak lurus akan mengarah ke kiblat (Ka'bah). Pengukuran semacam ini adalah mengukuran yang sangat mudah dan tidak membutuhkan biaya.

b. Menggunakan rumus ilmu ukur segitiga bola (Trigonometri) yaitu :

Cotan $\mathrm{B}=\operatorname{cotan} \mathrm{b} \sin \mathrm{a} / \sin \mathrm{C}-$ $\operatorname{coc}$ a cotan $\mathrm{C}$.

Umpama ingin mengetahui berapa derajat arah kiblat kota Parepare, maka langkah pertama data harus dipersiapkan yaitu data lintang tempat $(\varphi)$ dan data bujur tempat $(\lambda)$, data lintang Makkah/Ka'bah ( $\varphi)$ dan data bujur Makkah/Ka'bah $(\lambda)$.

Data:

Lintang Tempat $(\varphi)=4^{0} 01^{\prime} \mathrm{S}$

Bujur Tempat $(\lambda)=119^{\circ} 40^{\prime}$ BT

Lintang Makkah $(\varphi)=21^{0} 25^{\prime} \mathrm{U}$

Bujur Makkah $(\lambda)=39^{0} 50^{\prime} \mathrm{BT}$ 
Keterangan :

a. $90^{\circ}-\mathrm{Lo}=90^{\circ}-\left(-4^{0} 01^{\prime}\right)=94^{0} 01^{\prime}$

b. $90^{0}-\mathrm{L}_{\mathrm{M}}=90^{0}-\left(21^{0} 25^{\prime}\right)=68^{0} 35^{\prime}$

c. $b_{M}-b_{O}=119^{0} 40^{\prime}-39^{0} 500^{\prime}=79^{0} 50^{\prime}$

Cotg $<\mathrm{UOM}=$

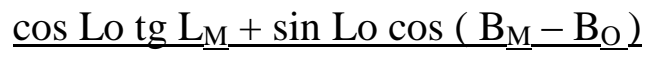

$\operatorname{Sin}\left(\mathrm{B}_{\mathrm{M}}-\mathrm{B}_{\mathrm{O}}\right)$

$\operatorname{Tan}^{-1}\left(\left(\cos -4^{0} 01^{\prime} \times \operatorname{tg} 21^{0} 25^{\prime}+\sin \right.\right.$ $\left.\left.4^{0} 01^{\prime} x \cos 79^{0} 50^{\prime}\right) / \sin 79^{0} 50^{\prime}\right)=$ shif ${ }^{0, "} 22^{0} 17^{\prime} 49.55^{\prime \prime}$

Jadi arah kiblat kota Parepare adalah :

$22^{0} 17^{\prime} 49.55^{\prime \prime}$ di ukur dari titik Barat ke Utara, atau

$67^{0} 42 ' 10.45 "$ di ukur dari titik Utara ke Barat, atau Azimuthnya $292^{0} 17 ’ 49.55^{\prime \prime}$ UTSB.

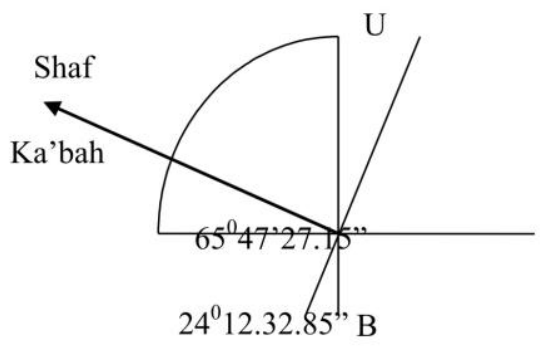

Shaf $\mathrm{S}$

c. Menggunakan kaidah Goniometri:

$\mathrm{BK}=\tan$ Kiblat $\mathrm{x} P B$

Barat

Kiblat $=22^{0} 17^{\prime} 49.55^{\prime \prime}$

$41.00 \mathrm{~cm}$ (dibulatkan)

$$
\begin{array}{rl}
\mathrm{B} & \mathrm{K} \\
\mathrm{PB}=100 \mathrm{~cm} & \\
\mathrm{BK}=\tan 22^{0} 17^{\prime} 49.55^{\prime \prime} \times 100
\end{array}
$$

$$
=1,0070705 \mathrm{~cm}
$$

$1 \mathrm{PK}=\mathrm{ARAH}$ KIBLAT

Barat

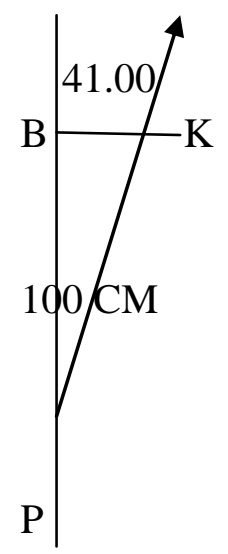

Timur

2. $\mathrm{BC}=\tan$ Kiblat $\times \mathrm{AB}$

Kiblat $=67^{0} 42^{\prime} 10.45^{\prime \prime}$

$$
\begin{aligned}
\mathrm{AB} & =100 \mathrm{~cm} \\
\mathrm{BC} & =\tan 67^{0} 42^{\prime} 10.45 \times 100 \\
& =243,8603845 \mathrm{~cm} \\
\mathrm{AC} & =\text { ARAH KIBLAT }
\end{aligned}
$$

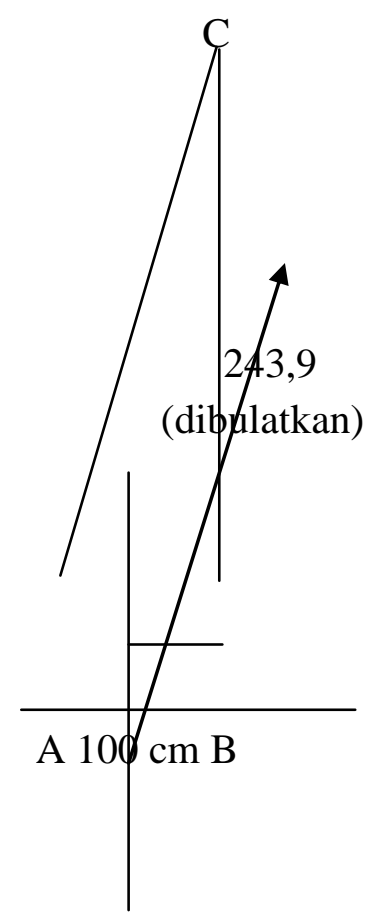

$\mathrm{cm}$ 


\section{PENUTUP}

Dengan adanya gempa bumi terus menerus sehingga lempeng-lempeng bumi bergeser dan pergeseran itu relatif sangat kecil dan membutuhkan waktu yang sangat lama, maka tidak merubah arah kiblat suatu masjid dari posisi semula, sedang posisi masjid yang arah kiblatnya berubah (tidak akurat lagi) setelah diadakannya pengukuran ulang itu disebabkan pada saat membangun pengukurannya kurang benar.

Menurut pendapat Imam Syafi'i dan sebagian besar ulama madzhabnya bahwa pengaturan shalatnya baik bagi orang yang tahu Ka'bah atau bagi orang yang kawasannya jauh dari Makkah, termasuk Indonesia tetap harus menghadap ke 'ain al-Ka'bah bahkan manakala kaifiyah shalatnya mengikuti Syafi'iyah, maka pengaturan menghadapnya ke 'ain al$K a$ 'bah. Sedangkan menurut Jumhur Fuqaha bagi orang yang kawasannya jauh dari Makkah, maka pengaturan shalatnya cukup menghadap ke jihat al- Ka'bah. Pendapat Jumhur ulama tampaknya berbeda dengan Imam Syafi'i dan sebagian besar muridnya bahwa menghadap ke jihat al- Ka'bah sebenarnya kalau ditarik benang lurus ke Ka'bah pasti akan mengenai 'ain al-Ka'bah.

Bagi umat Islam Indonesia yang kawasannya sebelah timur Makkah, selama shalatnya menghadap ke arah barat tetap sah, namun jika keabsahan shalatnya ingin lebih sempurna maka harus berusaha untuk menghadapkan dirinya ke 'ain al-Ka'bah yaitu ke arah barat laut sesuai dengan posisi kawasan masing-masing, dan bagi masjid/mushalla yang arah kiblatnya masih kurang tepat (akurat) diupayakan untuk menata ulang shafnya dan tidak perlu membongkar bangunan masjidnya.

\section{Catatan Akhir:}

${ }^{1}$ Sayid Sabiq, Fiqh al-Sunnah, (Beirut: Dar al-Fikr, 1983, hal. 104-111; Ibn Rusyd, Bidayah al- Mujtahid wa Nihayah alMuqtashid, (Beirut : Dar al-Fikr, tt), Jilid I, hal. 80; Wahbah al-Zuhaili, al-Fiqh al-Islami wa adillatuhu, (Bairut: Dar al-Fikr, 1999, jilid 1, hal. 758.

${ }^{1}$ Wawancara Prof. Dr. H. Thomas Djamaluddin, M.Sc. tanggal 12 Juli 2011.

${ }^{1}$ Pedoman dan Prosedur Penetapan Fatwa Majlis Ulama Indonesia; dalam bagian muqaddimah paragraf ke 4 .

${ }^{1}$ Asjmuni A. Rahman, Qaidah-Qaidah Fiqih (Qawa'idul Fiqhiyah) (Cet. I ; Jakarta: Bulan Bintang, 1976), h. 43.

${ }^{1}$ Al-Qur'an Dan Terjemahnya (Departemen Agama RI, th. 2005).

${ }^{1}$ Al-Qur'an Dan Terjemahnya (Departemen Agama RI, th. 2005).

${ }^{1} \mathrm{Abu}$ Abdillah Muhammad bin Isma'il bin Ibrahim ibn al-Mughirah bin Bardazbah al-Bukhary, Shahih al-Bukhari, (Juz I. Kairo: Dar al-Hadis, 2004), h. 110.

${ }^{1}$ Abu Abdillah Muhammad bin Isma'il bin Ibrahim ibn al-Mughirah bin Bardazbah al-Bukhary, Shahih al-Bukhari, h. 110.

${ }^{1}$ Imam Abi Husain Muslim bin Hajjaj ibn Muslim al-Qusyairi al-Naisaburi, al-Jami'us Shahih ( Juz I. Beirut : Dar al-Fikr, tt), h. 66.

${ }^{1}$ al-Baihaqie, al-Sunan al-Kubra (Juz II. Makkah: Maktabah Dar al-Baz, 1994), h. 9.

${ }^{1}$ Kekeliruan yang terjadi pada masa Nabi saw tidak disebabkan oleh ketidakakuratan dalam penentuan arah kiblat, tetapi terjadi karena adanya perubahan arah kiblat berdasarkan perintah Allah dari Masjid 
al-Aqsha di Yerussalam ke Masjid al Haram di Makkah.

${ }^{1}$ Hasjim Abbas, Klarifikasi Fatwa Majlis Ulama Indonesia Tentang Arah Kiblat (Makalah Seminar Nasional PK.PT. IPNUIPPNU IAIN Sunan Amplel Surabaya, 2010), h. 6.

${ }^{1}$ Pengukuran dilakukan pada tanggal 5 Juni 2017.

${ }^{1}$ Hasjim Abbas, Klarifikasi Fatwa Majlis Ulama Indonesia Tentang Arah Kiblat, h. 2

${ }^{1}$ Departemen Agama RI, Pedoman Penentuan Arah Kiblat (Jakarta, 1994/1995), h.3.

${ }^{1}$ Al-Jashas, Ahkamu al-Qur'an (Juz I. Beirut: Dar al- Kutub al-Arabi, 1335 H), h. 84-85, al-Qurtubi, al-Jami li Ahkami alQur'an (Juz II. Beirut: Dar al-Kutub al-Arabi, $1387 \mathrm{H})$, h. 158.

${ }^{1}$ Wahbah al-Zuhaili, Tafsir al-Munir (Juz II. Beirut : Dar al-Fikr al-Mu'ashir, 1991), h. 13-14.

${ }^{1}$ Muhammad Mutawalli al-Sya'rawi, 100 Sualin wa Jawabin (Juz I. Kairo : Maktabah al-Turats al-Islami, 1403 H). h. 45.

${ }^{1}$ Hasjim Abbas, h. 3

1 al-Ghazali, al- Wajiz fi Fiqhi Madzahib al-Imam al-Syafi'I (Beirut: Dar al-Fikr, 1994), h. 33; Ba'alwi, tt. Baghyah al-Mustarsyidin (Bandung: al-Ma'arif), h. 39.

1 al-Syairazi, al-Muhadzab fi Fiqhi alImam al-Syafi'I (Beirut: Dar al-Fikr, tt), h. 6.

${ }^{1}$ An-Nawawi, tt. al-Majmu' Syarh alMuhadzab (Jilid III, Jeddah: Maktabah alIrsyad, ), h. 202.

${ }^{1}$ Wahbah Al-Zuhaili, loc. cit.

${ }^{1}$ An-Nawawi, h..203.

${ }^{1}$ At-Tirmidzi, Sunan at-Tirmidzi, (Juz I. Beirut: Dar al-Fikr, 2003), h. 363; Ibn Majah, Sunan Ibn Majah (Juz I. Beirut: Dar al-Fikr, 2004), h. 320; an-Nasa'i, Sunan an-Nasa'I (Juz IV. Beirut: Dar al-Fikr, 1999), h. 175.

${ }^{1}$ Wahbah al-Zuhaili, al-Fiqh alIslami wa Adillatuh (Jilid I. Damaskus: Dar alFikr, 1997), h.758; Lihat juga Ibn Rusyd, Bidayah al-Mujtahid wa Nihayah alMuqtashid (Jilid I. Beirut:Dar al-Fikr, tt), h. 80.
${ }^{1}$ Ibn Rusyd, Bidayah al-Mujtahid wa Nihayah al-Muqtashid.

${ }^{1}$ Imam al-Razi, Tafsir Fahru al-Razi (Juz IV. Beirut: Dar al-Fikr, 1985), h. 127.

\section{DAFTAR PUSTAKA}

Abbas, Hasjim. 2010. Klarifikasi Fatwa Majelis Ulama Indonesia Tentang arah Kiblat, Makalah.

Adlani, A. Nazri. et.al (tim Penyunting). 1997. Himpunan Fatwa Majelis Ulama Ulama Indonesia, MUI.

Ba'alwi, Baghyah al-Musytarsyidin. Bandung: Al-Ma'arif, tt.

Al-Baihaqie. 1994. al-Sunan alKubra, Makkah: Maktabah Dar al-Baz, Juz II4.

Al-Bukhari, Shahih Bukhari, Jilid I. 2004. Kairo: Dar al Hadis.

Departemen Agama RI. 2005. AlQur'an dan Terjamahnya, Jakarta. Departemen Agama RI, 1994/1995. Pedoman Penentuan Arah Kiblat, Jakarta.

Djamaluddin, Thomas. 2010. Lembaga Antariksa dan Penerbangan Nasional (LAPAN), Bandung.

Al-Ghazali. 1994. Al-Wajiz fi Fiqhi Madzahib al-Imam al-Syafi'i, Beirut: Dar al-Fikr.

Al-Jashas. 1335 H. Ahkamu alQur'an. Beirut: Dar al-Kutub alArabi, I.

Muslim. al-Jami' ash-Shahih, Juz I, Beirut: Dar al-Fikr, tt.

An-Nawawi. al-Majmu' Syarh alMuhadzab, Jilid III, Jeddah: Maktabah al-Irsyad, tt.

Al-Qurtubi. 1378 H. al-Jami li Ahkami 
al-Qur'an. Beirut: Dar al-Kutub, al-Arabi, Juz II.

Rahman, Asmuni, A.1976. QaidaQaidah Fiqh (Qawaid alFiqhiyah), Cet. I. Jakarta: Bulan Bintang.

Al-Razi, Fahruddin. 1985. Tafsir Fahru al-Razi. Juz IV. Beirut: Dar al-Fikr.

Rusyd, Ibn. tt. Bidayah al-Mujtahid wa Nihayah al-Muqtashid. Jilid I. Beirut: Dar al-Fikir.

Sabiq, Sayid. 1983. Fiqih al-Sunnah. Beirut: Dar al-Fikr.

Al-Syairazi. tt. Al-Muhadzab fi Fiqhi al-Imam al-Syafi'i. Beirut: Dar alFikr.
Al-Sya'rani, M. Mutawalli. 1403 H. 100 Sualin wa Jawabin, I. Kairo, Maktabah al-Turats al-Islami.

Al-Tirmidzi. 2003. Sunan al-Tirmidzi, Juz I, Beirut, Dar al-Fikr.

Al-Zuhaili, Wahbah. 1991. Tafsir AlMunir. Juz XV. Beirut: Dar alFikr al-Mu'ashir.

--------. 1997. Jilid I. al-Fiqh al-Islami wa Adillatuhu, Damaskus: Dar alFikr. 